\title{
Desempeño docente y el aprendizaje de los estudiantes de educación inicial de la Facultad de Educación de la Universidad Nacional José Faustino Sánchez Carrión
}

\section{Teaching performance and learning of the students of initial education of the Faculty of Education of the National University Jose Faustino Sanchez Carrion}

\author{
Wendey Isolina Torres López
}

\begin{abstract}
RESUMEN
Objetivo: Conocer la relación del desempeño docente y el aprendizaje de los estudiantes del Ill ciclo de la Escuela Profesional de Educación Inicial de la Facultad de Educación de la Universidad Nacional José Faustino Sánchez Carrión, Material y Métodos: Para realizar un mejor trabajo a nivel educativo y familiar debido a la gran influencia que ellos ejercen en la formación profesional de los estudiantes., teniendo como población un total de 30 estudiantes, no se toma la muestra debido a que en la investigación se trabaja con toda la población. El estudio planteado es de tipo relacional sin intervención perspectivo. Resultado: La existencia del problema debido a que se comprobó la relación entre las variables y la comprobación de las hipótesis planteadas demostrando que existe una relación significativa entre desempeño docente y aprendizaje de los estudiantes universitarios fortaleciendo las capacidades de los docentes universitarios y las estudiantes que irán acorde con los avances tecnológicos, científicos en marcados a los desafíos sociales actuales. Conclusiones: Se establecen las características generales y básicos que deben realizar para desarrollar un proceso de enseñanza-aprendizaje de calidad, brindando las oportunidades de aprendizaje a todos los estudiantes y contribuir, mediante su formación, a construir la sociedad que aspiramos para nuestro país.
\end{abstract}

Palabras clave: Desempeño docente, aprendizaje de los estudiantes.

\begin{abstract}
Objective: To know the relation of the teaching performance and the learning of the students of the III cycle of the School of Initial Education of the Faculty of Education of the National University José Faustino Sánchez Carrión. Material and Methods: To do a better job at educational level and family due to the great influence that they exert in the professional formation of the students., having as a population a total of 30 students, the sample is not taken because the research works with the entire population. The study proposed is of a relational type without perspective intervention. Result: The existence of the problem due to the fact that the relationship between the variables and the verification of the hypotheses raised was demonstrated demonstrating that there is a significant relationship between teacher performance and learning of university students, strengthening the capacities of university teachers and the students that will go according to technological advances, scientists in marked to the current social challenges. Conclusions: The general and basic characteristics that must be carried out to develop a quality teaching-learning process are established, providing learning opportunities for all students and contributing, through their training, to build the society we aspire for our country
\end{abstract}

Keywords: Teaching performance, student learning.

\section{INTRODUCCIÓN}

En la actualidad uno de los múltiples retos de la educación, es dar respuesta a los profundos cambios sociales, económicos y culturales del mundo globalizado del que somos parte. Así también, responder a la demanda específica sobre la función del docente, nos confronta con un reto singular: realizar cambios en la realidad de la profesión docente, es decir, en su identidad profesional, en su formación y su cultura, en los paradigmas que guían sus prácticas pedagógicas. Los motivos del cambio son estructurales, pues obedecen a transformaciones en la sociedad, en la cultura, en la producción del saber y en la necesidad de contribuir, desde la educación, a la conformación de sociedades más equitativas, democráticas y con altos niveles de desarrollo humano.

Son necesarios cambios profundos en la práctica de la enseñanza, en los mecanismos para profesionalizar el trabajo docente y revalorar el saber pedagógico de los maestros en la sociedad. Ése es el desafío que el Estado Peruano, los docentes y la sociedad requieren afrontar de manera concertada, colaborativa y sostenida. En esta orientación, se requiere concordar previamente una visión prospectiva de la profesión docente con los diversos actores involucrados en el ejercicio, promoción, desarrollo y regulación de la docencia.

Es así que Palomino (2012), sostiene que: "El desempeño docente se entiende como el cumplimiento de sus funciones; éste se halla determinado por factores asociados al propio docente, al estudiante y al entorno. Así mismo, el desempeño se ejerce en diferentes campos o niveles: el contexto socio- cultural, el entorno institucional, el ambiente de aula y sobre el propio docente una acción mediante una acción reflexiva". ( $p$. 31)

Para nuestro caso, es el acto por el cual un profesional asume un compromiso para garantizar la adecuada preparación de los profesionales en las universidades.

Tomando en consideración estas afirmaciones, en el ámbito laboral educativo se hace necesario el empleo de esta comunicación para lograr con éxito establecer buenas relaciones entre los integrantes de la comunidad.

\section{MATERIALYMÉTODO}

Se aplicó un Diseño no experimental de alcance relacional sin intervención prospectivo porque estudia las características del desempeño docente y su relación con el aprendizaje de educación inicial de la facultad de educación de la universidad nacional José Faustino Sánchez Carrión de Huacho.

La toma de muestras se realizará de acuerdo a las experiencias internacionales y nacionales, través de cuestionarios y encuestas

\section{Población y Muestra.}

Para la investigación se tomó como población y muestra al total de estudiantes (30) del III Ciclo de Educación Inicial de la Facultad de Educación de la Universidad Nacional José Faustino Sánchez Carrión.

Recibido:28/06/19 Aprobado:31/07/19




\section{RESULTADOS}

Variable Dependiente: DesempeñoAcadémico.

\section{Tabla 1:}

¿En qué medida el docente relaciona la teoría con los trabajos prácticos?

\begin{tabular}{lllllc}
\hline & Frec & Porc & $\begin{array}{c}\text { Porcentaje } \\
\text { válido }\end{array}$ & $\begin{array}{c}\text { Porcentaje } \\
\text { acumulado }\end{array}$ \\
\hline Válido & Casi nunca & 2 & 6,7 & 6,7 & 6,7 \\
& pocas veces & 14 & 46,7 & 46,7 & 53,3 \\
Muchas Veces & 7 & 23,3 & 23,3 & 76,7 \\
Casi siempre & 6 & 20,0 & 20,0 & 96,7 \\
Siempre & 1 & 3,3 & 3,3 & 100,0 \\
Total & 30 & 100,0 & 100,0 & \\
\hline
\end{tabular}

Del total de estudiantes encuestados el $6,7 \%$ respondieron casi nunca a la pregunta en qué medida el docente relaciona la teoría con los trabajos prácticos, $46,7 \%$ respondieron pocas veces, 23,3 respondieron muchas veces, $20,0 \%$ respondieron casi siempre y 3,3 dieron como respuesta siempre.

Tabla 2

El docente incentiva la investigación en función del desarrollo de los temas tratados en clase

\begin{tabular}{cccccc}
\hline & Frec & Porc & $\begin{array}{c}\text { Porcentaje } \\
\text { válido }\end{array}$ & $\begin{array}{c}\text { Porcentaje } \\
\text { acumulado }\end{array}$ \\
\hline Válido & Casi nunca & 2 & 6,7 & 6,7 & 6,7 \\
& pocas veces & 6 & 20,0 & 20,0 & 26,7 \\
Muchas Veces & 11 & 36,7 & 36,7 & 63,3 \\
Casi siempre & 11 & 36,7 & 36,7 & 100,0 \\
Total & 30 & 100,0 & 100,0 & \\
\hline
\end{tabular}

$6,7 \%$ refieren que el docente inventiva la investigación en función del desarrollo de los temas tratados en clases, el $20,0 \%$ respondieron pocas veces, un $36,7 \%$ muchas veces y el $36,7 \%$ casi siempre

\section{Tabla 3}

Evalúe el grado en que el docente dirige adecuadamente las discusiones en grupo.

\begin{tabular}{lllllr}
\hline & Frec & Porc & $\begin{array}{c}\text { Porcentaje } \\
\text { válido }\end{array}$ & $\begin{array}{c}\text { Porcentaje } \\
\text { acumulado }\end{array}$ \\
\hline Válido & Casi nunca & 5 & 16,7 & 16,7 & 16,7 \\
& pocas veces & 14 & 46,7 & 46,7 & 63,3 \\
Muchas Veces & 7 & 23,3 & 23,3 & 86,7 \\
Casi siempre & 2 & 6,7 & 6,7 & 93,3 \\
Siempre & 2 & 6,7 & 6,7 & 100,0 \\
Total & 30 & 100,0 & 100,0 & \\
\hline
\end{tabular}

En la Tabla 3 se aprecia que del total de estudiantes encuestados $16,7 \%$ refieren que casi nunca el docente dirige adecuadamente las discusiones en grupo, $46,7 \%$ pocas veces, el $23,3 \%$ muchas veces, el $6,7 \%$ casi siempre y $6,7 \%$ siempre

\section{Tabla 4}

El docente plantea sus preguntas que permiten al estudiante usar sus criterios

\begin{tabular}{lllllr}
\hline & Frec & Porc & $\begin{array}{c}\text { Porcentaje } \\
\text { válido }\end{array}$ & $\begin{array}{r}\text { Porcentaje } \\
\text { acumulado }\end{array}$ \\
\hline Válido & Casi nunca & 3 & 10,0 & 10,0 & 10,0 \\
& pocas veces & 13 & 43,3 & 43,3 & 53,3 \\
Muchas Veces & 4 & 13,3 & 13,3 & 66,7 \\
Casi siempre & 7 & 23,3 & 23,3 & 90,0 \\
Siempre & 3 & 10,0 & 10,0 & 100,0 \\
Total & 30 & 100,0 & 100,0 & \\
\hline
\end{tabular}

Del total de estudiantes encuestados el $10,0 \%$ refieren que casi nunca el docente plantea sus preguntas que permite al estudiante usar sus criterios, $43,3 \%$ pocas veces, $13,3 \%$ respondieron muchas veces, $23,3 \%$ casi siempre y un $10.0 \%$ siempre. (Tabla 4)

\section{Tabla 5}

¿En qué medida la técnica empleada por el docente le permite ampliar sus conocimientos?

\begin{tabular}{lllllc}
\hline & Frec & Porc & $\begin{array}{c}\text { Porcentaje } \\
\text { válido }\end{array}$ & $\begin{array}{c}\text { Porcentaje } \\
\text { acumulado }\end{array}$ \\
\hline Válido & Nunca & 1 & 3,3 & 3,3 & 3,3 \\
& Casi nunca & 1 & 3,3 & 3,3 & 6,7 \\
Pocas veces & 15 & 50,0 & 50,0 & 56,7 \\
Muchas veces & 7 & 23,3 & 23,3 & 80,0 \\
Casi siempre & 5 & 16,7 & 16,7 & 96,7 \\
Siempre & 1 & 3,3 & 3,3 & 100,0 \\
Total & 30 & 100,0 & 100,0 & \\
\hline
\end{tabular}

En la Tabla 5 se observa que del total de estudiantes encuestados el $3,3 \%$ refieren nunca a la pregunta, en qué medida la técnica empleada por el docente le permite ampliar sus conocimientos, el 3,3 respondieron casi nunca, el 50,0\% pocas veces, el $23,3 \%$ muchas veces, el $16,7 \%$ casi siempre y $3.3 \%$ siempre.

\section{Tabla 6}

¿En qué medida el docente incentiva la participación de los estudiantes en clases?

\begin{tabular}{llcccc}
\hline & Frec & Porc & $\begin{array}{c}\text { Porcentaje } \\
\text { válido }\end{array}$ & $\begin{array}{c}\text { Porcentaje } \\
\text { acumulado }\end{array}$ \\
\hline Válido & Nunca & 1 & 3,3 & 3,3 & 3,3 \\
Casi nunca & 3 & 10,0 & 10,0 & 13,3 \\
Pocas veces & 9 & 30,0 & 30,0 & 43,3 \\
Muchas veces & 11 & 36,7 & 36,7 & 80,0 \\
Casi siempre & 5 & 16,7 & 16,7 & 96,7 \\
Siempre & 1 & 3,3 & 3,3 & 100,0 \\
\hline
\end{tabular}

Del total de estudiantes encuestados el 3,3\% refieren nunca a la pregunta en qué medida el docente incentiva la participación de los estudiantes en clases, el 10,0\% casi nunca, el $30,0 \%$ pocas veces, el $36,7 \%$ muchas veces, el $16,7 \%$ casi siempre y el $3,3 \%$ siempre. (Tabla 6 ) 
Tabla 7

¿En qué grado de las actividades desarrolladas en clases le permite ampliar sus conocimientos?

\begin{tabular}{llcrrr}
\hline & Frec & Porc & $\begin{array}{c}\text { Porcentaje } \\
\text { válido }\end{array}$ & $\begin{array}{c}\text { Porcentaje } \\
\text { acumulado }\end{array}$ \\
\hline Válido & Casi nunca & 5 & 16,7 & 16,7 & 16,7 \\
pocas veces & 9 & 30,0 & 30,0 & 46,7 \\
Muchas Veces & 8 & 26,7 & 26,7 & 73,3 \\
Casi siempre & 8 & 26,7 & 26,7 & 100,0 \\
Total & 30 & 100,0 & 100,0 & \\
\hline
\end{tabular}

En la Tabla 7 se puede observar que del total de estudiantes encuestados el $16,7 \%$ respondieron casi nunca a la pregunta en qué grado de las actividades desarrolladas en clases le permite ampliar sus conocimientos, $30,0 \%$ respondieron pocas veces, $26,7 \%$ respondieron muchas veces y $26,7 \%$ respondieron casi siempre.

Tabla 8

¿En qué medida el docente diseña un medio didáctico?

\begin{tabular}{|c|c|c|c|c|c|}
\hline & & Frec & Porc & $\begin{array}{l}\text { Porcentaje } \\
\text { válido }\end{array}$ & $\begin{array}{l}\text { Porcentaje } \\
\text { acumulado }\end{array}$ \\
\hline \multirow[t]{6}{*}{ Válido } & Casi nunca & 2 & 6,7 & 6,7 & 6,7 \\
\hline & pocas veces & 12 & 40,0 & 40,0 & 46,7 \\
\hline & Muchas Veces & 9 & 30,0 & 30,0 & 76,7 \\
\hline & Casi siempre & 5 & 16,7 & 16,7 & 93,3 \\
\hline & Siempre & 2 & 6,7 & 6,7 & 100,0 \\
\hline & Total & 30 & 100,0 & 100,0 & \\
\hline
\end{tabular}

Del total de estudiantes encuestados el 6,7\% respondieron casi nunca, el $40,0 \%$ pocas veces, el $30,0 \%$ muchas veces, el $16,7 \%$ casi siempre y el $6,7 \%$ respondieron siempre, a la pregunta en qué medida el docente diseña un medio didáctico. (Tabla 8)

Tabla 9

¿En qué medida el docente elabora materiales didácticos?

\begin{tabular}{|c|c|c|c|c|c|}
\hline & & Frec & Porc & $\begin{array}{c}\text { Porcentaje } \\
\text { válido }\end{array}$ & $\begin{array}{l}\text { Porcentaje } \\
\text { acumulado }\end{array}$ \\
\hline \multirow[t]{6}{*}{ Válido } & Casi nunca & 2 & 6,7 & 6,7 & 6,7 \\
\hline & pocas veces & 12 & 40,0 & 40,0 & 46,7 \\
\hline & Muchas Veces & 9 & 30,0 & 30,0 & 76,7 \\
\hline & Casi siempre & 5 & 16,7 & 16,7 & 93,3 \\
\hline & Siempre & 2 & 6,7 & 6,7 & 100,0 \\
\hline & Total & 30 & 100,0 & 100,0 & \\
\hline
\end{tabular}

Del total de estudiantes encuestados el 6,7\% respondieron casi nunca a la pregunta en qué medida el docente elabora materiales didácticos, el $40,0 \%$ respondieron pocas veces, el $30,0 \%$ muchas veces, el $16,7 \%$ casi siempre y el $6.7 \%$ respondió siempre.

Tabla 10

¿En qué medida el docente selecciona los medios didácticos?

\begin{tabular}{ccccc}
\hline & Frec & Porc & $\%$ válido & $\%$ acumulado \\
\hline Válido Casi nunca & 3 & 10,0 & 10,0 & 10,0 \\
pocas veces & 10 & 33,3 & 33,3 & 43,3 \\
Muchas Veces & 10 & 33,3 & 33,3 & 76,7 \\
Siempre & 2 & 6,7 & 6,7 & 100,0 \\
Total & 30 & 100,0 & 100,0 & \\
\hline
\end{tabular}

Se puede observar que del total de estudiantes encuestados el $10,0 \%$ respondieron casi nunca a la pregunta En qué medida el docente selecciona los medios didácticos, el 33,3\% respondieron pocas veces, el $33,3 \%$ respondieron muchas veces, el $16,7 \%$ respondieron casi siempre y $6,7 \%$ respondieron siempre.

\section{Tabla 11}

¿En qué medida el docente selecciona los materiales

\begin{tabular}{lllllc}
\hline & Frec & Porc & $\begin{array}{c}\text { Porcentaje } \\
\text { válido }\end{array}$ & $\begin{array}{c}\text { Porcentaje } \\
\text { acumulado }\end{array}$ \\
\hline Válido & Nunca & 1 & 3,3 & 3,3 & 3,3 \\
& Casi nunca & 5 & 16,7 & 16,7 & 20,0 \\
& Pocas veces & 6 & 20,0 & 20,0 & 40,0 \\
Muchas veces & 14 & 46,7 & 46,7 & 86,7 \\
Casi siempre & 2 & 6,7 & 6,7 & 93,3 \\
Siempre & 2 & 6,7 & 6,7 & 100,0 \\
Total & 30 & 100,0 & 100,0 & \\
\hline
\end{tabular}

El 3,3\% respondieron nunca a la afirmación en qué medida el docente selecciona los materiales didácticos, el $16,7 \%$ respondieron casi nunca, el $20,0 \%$ respondieron pocas veces, el $46,7 \%$ respondieron muchas veces, el 6,7 respondieron casi siempre y el $6,7 \%$ respondieron siempre.

Tabla 12

¿En qué medida el docente clasifica los materiales didácticos?

\begin{tabular}{llcccc}
\hline & Frec & Porc & $\begin{array}{c}\text { Porcentaje } \\
\text { válido }\end{array}$ & $\begin{array}{c}\text { Porcentaje } \\
\text { acumulado }\end{array}$ \\
\hline Válido & Casi nunca & 3 & 10,0 & 10,0 & 10,0 \\
& pocas veces & 8 & 26,7 & 26,7 & 36,7 \\
Muchas Veces & 14 & 46,7 & 46,7 & 83,3 \\
Casi siempre & 4 & 13,3 & 13,3 & 96,7 \\
Siempre & 1 & 3,3 & 3,3 & 100,0 \\
Total & 30 & 100,0 & 100,0 & \\
\hline
\end{tabular}

Del total de estudiantes respondieron el $10,0 \%$ casi nunca, el $26,7 \%$ pocas veces, el $46,7 \%$ respondieron muchas veces, el $13,3 \%$ casi siempre y $3,3 \%$ respondieron siempre, a la pregunta en qué medida el docente clasifica los materiales didácticos.

Tabla 13

¿En qué medida el docente emplea los medios didácticos?

\begin{tabular}{llllcc}
\hline & Frec & Porc & $\begin{array}{c}\text { Porcentaje } \\
\text { válido }\end{array}$ & $\begin{array}{c}\text { Porcentaje } \\
\text { acumulado }\end{array}$ \\
\hline Válido & Nunca & 1 & 3,3 & 3,3 & 3,3 \\
& Casi nunca & 2 & 6,7 & 6,7 & 10,0 \\
& Pocas veces & 12 & 40,0 & 40,0 & 50,0 \\
Muchas veces & 10 & 33,3 & 33,3 & 83,3 \\
Casi siempre & 5 & 16,7 & 16,7 & 100,0 \\
\hline & 30 & 100,0 & 100,0 & \\
\hline
\end{tabular}

Se puede observar que del total de estudiantes encuestados el $3,3 \%$ respondieron nunca, el $6,7 \%$ respondieron casi nunca, el $40,0 \%$ respondieron pocas veces, el 33,3\% mencionaron muchas veces y el $16,7 \%$ casi siempre, a la pregunta, en qué medida el docente emplea los medios didácticos. 
Tabla 14

¿En qué medida el docente emplea los materiales didácticos?

\begin{tabular}{llllcc}
\hline & Frec & Porc & $\begin{array}{c}\text { Porcentaje } \\
\text { válido }\end{array}$ & $\begin{array}{c}\text { Porcentaje } \\
\text { acumulado }\end{array}$ \\
\hline Válido Nunca & 1 & 3,3 & 3,3 & 3,3 \\
& Casi nunca & 4 & 13,3 & 13,3 & 16,7 \\
Pocas veces & 8 & 26,7 & 26,7 & 43,3 \\
Muchas veces & 11 & 36,7 & 36,7 & 80,0 \\
Casi siempre & 6 & 20,0 & 20,0 & 100,0 \\
\hline
\end{tabular}

Del total de estudiantes encuestados el 3,3\% respondieron nunca, el $13,3 \%$ respondieron casi nunca, el $26,7 \%$ respondieron pocas veces, el $36,6 \%$ respondieron muchas veces, el $20,0 \%$ respondieron casi siempre a la pregunta, en qué medida el docente emplea los materiales didácticos.

\section{Tabla 15}

Evalúe el grado en que el docente domina el curso

\begin{tabular}{llllcc}
\hline & Frec & Porc & $\begin{array}{c}\text { Porcentaje } \\
\text { válido }\end{array}$ & $\begin{array}{c}\text { Porcentaje } \\
\text { acumulado }\end{array}$ \\
\hline Válido Nunca & 1 & 3,3 & 3,3 & 3,3 \\
& Casi nunca & 2 & 6,7 & 6,7 & 10,0 \\
Pocas veces & 10 & 33,3 & 33,3 & 43,3 \\
Muchas veces & 7 & 23,3 & 23,3 & 66,7 \\
Casi siempre & 7 & 23,3 & 23,3 & 90,0 \\
Siempre & 3 & 10,0 & 10,0 & 100,0 \\
\hline
\end{tabular}

Del total de encuestados $3.3 \%$ estudiantes respondieron nunca, el $6,7 \%$ casi nunca, el $33,3 \%$ pocas veces, el $23,3 \%$ muchas veces, el $23,3 \%$ casi siempre, el $10,0 \%$ siempre a la pregunta de que si el docente domina el curso.

\section{Tabla 16}

Evalúe el grado en el que el docente se expresa en forma clara yprecisa

\begin{tabular}{llllcc}
\hline & Frec & Porc & $\begin{array}{c}\text { Porcentaje } \\
\text { válido }\end{array}$ & $\begin{array}{c}\text { Porcentaje } \\
\text { acumulado }\end{array}$ \\
\hline Válido & Casi nunca & 2 & 6,7 & 6,7 & 6,7 \\
& pocas veces & 8 & 26,7 & 26,7 & 33,3 \\
Muchas Veces & 9 & 30,0 & 30,0 & 63,3 \\
Casi siempre & 9 & 30,0 & 30,0 & 93,3 \\
Siempre & 2 & 6,7 & 6,7 & 100,0 \\
Total & 30 & 100,0 & 100,0 & \\
\hline
\end{tabular}

Del total de estudiantes encuestados el 6,7\% respondieron que casi nunca el docente asiste y es puntual a sus sesiones de clase, el $26,7 \%$ respondieron pocas veces, el $30,0 \%$ respondieron muchas veces, el $30,0 \%$ respondieron casi siempre y el $6,7 \%$ respondieron siempre.

\section{Tabla 17}

El docente estimula el desarrollo de valores, de actitudes positivas y de comportamientos propios de un profesional

\begin{tabular}{llllcc}
\hline & Frec & Porc & $\begin{array}{c}\text { Porcentaje } \\
\text { válido }\end{array}$ & $\begin{array}{c}\text { Porcentaje } \\
\text { acumulado }\end{array}$ \\
\hline Válido & Casi nunca & 1 & 3,3 & 3,3 & 3,3 \\
& pocas veces & 11 & 36,7 & 36,7 & 40,0 \\
Muchas Veces & 11 & 36,7 & 36,7 & 76,7 \\
Casi siempre & 2 & 6,7 & 6,7 & 83,3 \\
Siempre & 5 & 16,7 & 16,7 & 100,0 \\
Total & 30 & 100,0 & 100,0 & \\
\hline
\end{tabular}

Se puede observar que del total de estudiantes encuestados el 3,3\% respondieron casi nunca a la pregunta si el docente estimula el desarrollo de valores, de actitudes positivas y de comportamientos propios de un profesional, el $36,7 \%$ respondió pocas veces, el $36,7 \%$ respondió muchas veces, el $6,7 \%$ respondió casi siempre y el $16,7 \%$ respondió siempre.

\section{Tabla 18:}

Evalúe el grado en que el docente tiene respeto a las opiniones de los estudiantes

\begin{tabular}{|c|c|c|c|c|c|}
\hline & & Frec & Porc & $\begin{array}{c}\text { Porcentaje } \\
\text { válido }\end{array}$ & $\begin{array}{l}\text { Porcentaje } \\
\text { acumulado }\end{array}$ \\
\hline \multirow[t]{6}{*}{ Válido } & Casi nunca & 2 & 6,7 & 6,7 & 6,7 \\
\hline & pocas veces & 7 & 23,3 & 23,3 & 30,0 \\
\hline & Muchas Veces & 13 & 43,3 & 43,3 & 73,3 \\
\hline & Casi siempre & 5 & 16,7 & 16,7 & 90,0 \\
\hline & Siempre & 3 & 10,0 & 10,0 & 100,0 \\
\hline & Total & 30 & 100,0 & 100,0 & \\
\hline
\end{tabular}

Del total de estudiantes encuestados el 6,7 respondieron casi nunca de la consulta si el docente tiene respeto a las opiniones de los estudiantes el $23,3 \%$ respondieron pocas veces, el $43,3 \%$ respondieron muchas veces, el $16,7 \%$ respondieron casi siempre y el $10,0 \%$ respondieron siempre.

\section{Tabla 19}

En que medida el docente asiste y es puntual a sus sesiones de clase

\begin{tabular}{|c|c|c|c|c|c|}
\hline & & Frec & Porc & $\begin{array}{l}\text { Porcentaje } \\
\text { válido }\end{array}$ & $\begin{array}{l}\text { Porcentaje } \\
\text { acumulado }\end{array}$ \\
\hline \multirow[t]{6}{*}{ Válido } & Casi nunca & 2 & 6,7 & 6,7 & 6,7 \\
\hline & pocas veces & 9 & 30,0 & 30,0 & 36,7 \\
\hline & Muchas Veces & 9 & 30,0 & 30,0 & 66,7 \\
\hline & Casi siempre & 9 & 30,0 & 30,0 & 96,7 \\
\hline & Siempre & 1 & 3,3 & 3,3 & 100,0 \\
\hline & Total & 30 & 100,0 & 100,0 & \\
\hline
\end{tabular}

Del total de encuestados el 6,7 estudiantes respondieron casi nunca a la pregunta en que medida el docente asiste y es puntual a sus sesiones de clases, el $30,0 \%$ respondieron pocas veces, el $30,0 \%$ respondieron muchas veces, el $30,0 \%$ respondieron casi siempre y el 3,3\% respondieron siempre 
Tabla 20

¿En que grado los docentes entregan las actas con oportunidad?

\begin{tabular}{|c|c|c|c|c|c|}
\hline & & Frec & Porc & $\begin{array}{c}\text { Porcentaje } \\
\text { válido }\end{array}$ & $\begin{array}{l}\text { Porcentaje } \\
\text { acumulado }\end{array}$ \\
\hline \multirow[t]{5}{*}{ Válido } & Pocas veces & 9 & 30,0 & 30,0 & 30,0 \\
\hline & Muchas veces & 10 & 33,3 & 33,3 & 63,3 \\
\hline & Casi siempre & 7 & 23,3 & 23,3 & 86,7 \\
\hline & Siempre & 4 & 13,3 & 13,3 & 100,0 \\
\hline & Total & 30 & 100,0 & 100,0 & \\
\hline
\end{tabular}

Del total de estudiantes encuestados el $30,0 \%$ respondieron pocas veces a la pregunta en qué grado los docentes entrega las actas con oportunidad, el 33,3\% respondieron muchas veces, el $23,3 \%$ respondieron casi siempre, mientras que el $13,3 \%$ respondieron siempre.

\section{Tabla 21}

Evalúe en qué medida el docente cumple y respeta el desarrollo del silabo.

\begin{tabular}{llllcc}
\hline & Frec & Porc & $\begin{array}{c}\text { Porcentaje } \\
\text { válido }\end{array}$ & $\begin{array}{c}\text { Porcentaje } \\
\text { acumulado }\end{array}$ \\
\hline Válido & Casi nunca & 1 & 3,3 & 3,3 & 3,3 \\
pocas veces & 10 & 33,3 & 33,3 & 36,7 \\
Muchas Veces & 5 & 16,7 & 16,7 & 53,3 \\
Casi siempre & 4 & 13,3 & 13,3 & 66,7 \\
Siempre & 10 & 33,3 & 33,3 & 100,0 \\
Total & 30 & 100,0 & 100,0 & \\
\hline
\end{tabular}

Del total de estudiantes encuestados el $3,3 \%$ respondieron casi nunca a la pregunta evalúe en qué medida el docente cumple y respeta el desarrollo del silabo, el $33,3 \%$ respondieron pocas veces, el $16,7 \%$ respondieron muchas veces, el $13,3 \%$ respondieron casi siempre y $33,3 \%$ respondieron siempre.

Tabla 22

En qué medida el docente tiene preparada sus clases.

\begin{tabular}{llllcc}
\hline & Frec & Porc & $\begin{array}{c}\text { Porcentaje } \\
\text { válido }\end{array}$ & $\begin{array}{c}\text { Porcentaje } \\
\text { acumulado }\end{array}$ \\
\hline Válido & Casi nunca & 1 & 3,3 & 3,3 & 3,3 \\
& pocas veces & 9 & 30,3 & 30,0 & 33,3 \\
Muchas Veces & 7 & 23,3 & 23,3 & 56,7 \\
Casi siempre & 4 & 13,3 & 13,3 & 70,0 \\
Siempre & 9 & 30,0 & 30,0 & 100,0 \\
Total & 30 & 100,0 & 100,0 & \\
\hline
\end{tabular}

Se aprecia que del total de estudiantes encuestados el 3,3\% respondieron casi nunca, el $30,0 \%$ respondieron pocas veces, el $23,3 \%$ respondieron muchas veces, el $13,3 \%$ respondieron casi siempre y el $30,0 \%$ respondieron siempre, a la pregunta en qué medida el docente tiene preparada sus clases.
Tabla 23

El docente es accesible y está dispuesto a atender consultas de los estudiantes.

\begin{tabular}{llllcc}
\hline & Frec & Porc & $\%$ válido & $\%$ acumulado \\
\hline Válido & Casi nunca & 2 & 6,7 & 6,7 & 6,7 \\
pocas veces & 7 & 23,3 & 23,3 & 30,0 \\
Muchas Veces & 2 & 6,7 & 6,7 & 36,7 \\
Casi siempre & 9 & 30,0 & 30,0 & 66,7 \\
Siempre & 10 & 33,3 & 33,3 & 100,0 \\
Total & 30 & 100,0 & 100,0 & \\
\hline
\end{tabular}

Del total de estudiantes encuestados el 6,7\% respondió casi nunca, el $23,3 \%$ respondió pocas veces, el $6,7 \%$ respondió muchas veces, el $30.0 \%$ respondió casi siempre, y el 33,3\% respondió siempre a la consulta si el docente es accesible y está dispuesto a atender consultas de los estudiantes.

\section{Tabla 24:}

En sus calificativos o notas obtenidas en el semestre anterior en las asignaturas profesionales ¿Son aprobatorias?

\begin{tabular}{llllrr}
\hline & Frec & Porc & $\begin{array}{c}\text { Porcentaje } \\
\text { válido }\end{array}$ & $\begin{array}{r}\text { Porcentaje } \\
\text { acumulado }\end{array}$ \\
\hline Válido & $\mathrm{Si}$ & 22 & 73,3 & 73,3 & 73,3 \\
& No & 2 & 6,7 & 6,7 & 80,0 \\
& Parcialmente & 6 & 20,0 & 20,0 & 100,0 \\
Total & 30 & 100,0 & 100,0 & \\
\hline
\end{tabular}

En la Tabla 24 se puede observar que del total de estudiantes encuestados el $73,3 \%$ respondieron sí, el $6,7 \%$ respondieron no y el $20,0 \%$ respondieron parcialmente a la consulta si sus calificativos o notas obtenidas en el semestre anterior en las asignaturas profesionales ¿son aprobatorias?

\section{Tabla 25}

Considera que ha logrado los objetivos educacionales en teoría.

\begin{tabular}{lccccc}
\hline & Frec & Porc & $\begin{array}{c}\text { Porcentaje } \\
\text { válido }\end{array}$ & $\begin{array}{c}\text { Porcentaje } \\
\text { acumulado }\end{array}$ \\
\hline Válido & Si & 1 & 3,3 & 3,3 & 3,3 \\
& No & 3 & 10,0 & 10,0 & 13,3 \\
& Parcialmente & 14 & 46,7 & 46,7 & 60,0 \\
\multicolumn{1}{l}{ Total } & 12 & 40,0 & 40,0 & 100,0 \\
\hline
\end{tabular}

Se puede observar que del total de estudiantes encuestados el $3,3 \%$ ha respondido algo en desacuerdo, el $10,0 \%$ ni de acuerdo ni en desacuerdo, el $46,7 \%$ algo de acuerdo y el $40,0 \%$ ha respondido muy de acuerdo a la consulta si considera que ha logrado los objetivos educacionales en teoría.

Tabla 26

Considera que ha logrado los objetivos educacionales en la prácticadocente.

\begin{tabular}{|c|c|c|c|c|c|}
\hline & & Frec & Porc & $\begin{array}{c}\text { Porcentaje } \\
\text { válido }\end{array}$ & $\begin{array}{l}\text { Porcentaje } \\
\text { acumulado }\end{array}$ \\
\hline \multirow[t]{5}{*}{ Válido } & $\begin{array}{l}\text { Muy en } \\
\text { desacuerdo }\end{array}$ & 1 & 3,3 & 3,3 & 3,3 \\
\hline & $\begin{array}{l}\text { Ni de acuerdo ni er } \\
\text { desacuerdo }\end{array}$ & 3 & 10,0 & 10,0 & 13,3 \\
\hline & Algo de acuerdo & 11 & 36,7 & 36,7 & 50,0 \\
\hline & Muy de acuerdo & 15 & 50,0 & 50,0 & 100 \\
\hline & Total & 30 & 100,0 & 100,0 & \\
\hline
\end{tabular}


Se puede observar que del total de estudiantes encuestados el $3,3 \%$ respondieron muy en desacuerdo, el $10,0 \%$ respondieron ni de acuerdo ni en desacuerdo, el $36,7 \%$ respondieron algo de acuerdo, el $50 \%$ respondieron muy de acuerdo a la pregunta si considera que ha logrado los objetivos educacionales en la práctica docente.

\section{Prueba de hipótesis}

\section{Hipótesis General}

\section{Desempeño docentes y aprendizaje de los estudiantes.}

Ho: El desempeño docente no se relaciona significativamente con el aprendizaje de los estudiantes Educación Inicial de la Facultad de Educación de la Universidad Nacional José Faustino Sánchez Carrión.

Hi: El desempeño docente se relaciona significativamente con el aprendizaje de los estudiantes de Educación inicial de la Facultad de Educación de la Universidad Nacional José Faustino Sánchez Carrión.

Nivel de confianza: $95 \%(a=0,05)$

Regla de decisión:

\section{* Si p < a; se rechaza la hipótesis nula}

* Si p >a; se acepta la hipótesis nula

\section{Análisis estadístico}

\section{Tabla 27}

\section{Prueba Chi-cuadrado}

\begin{tabular}{llll}
\hline \multicolumn{2}{c}{ Valor } & Gl & $\begin{array}{c}\text { Sig. Asist. } \\
\text { (2 caras) }\end{array}$ \\
\hline Chi-cuadrado de pearson & $17,899^{*}$ & 4 & 0,001 \\
Razón de verosimilitud & 18,026 & 4 & 0,001 \\
Asociación lineal por lineal & 10,849 & 1 & 0,001 \\
N de casos válidos & 30 & & \\
\hline
\end{tabular}

* 7 casillas $(77,8 \%)$ han esperado un recuento menor que 5 . El recuento mínimo esperado es 1,00.

Como el $p$-valor hallada es de 0,001 , y el Valor $p=0,001<0,05$, se afirma que el desempeño docente se relaciona significativamente con el aprendizaje de Educación Inicial de la Facultad de Educación de la Universidad Nacional José Faustino Sánchez Carrión

\section{Prueba de hipótesis específica 1}

Ho: Los métodos que aplica el docente no se relaciona significativamente con el aprendizaje de los estudiantes de Educación Inicial de la Facultad de Educación de la Universidad Nacional José Faustino Sánchez Carrión.

Hi: Los métodos que aplica el docente se relaciona significativamente con el aprendizaje de los estudiantes de Educación Inicial de la Facultad de Educación de la Universidad Nacional José Faustino Sánchez Carrión.

Tabla 28

Prueba Chi-Cuadrado

\begin{tabular}{llll}
\hline \multicolumn{1}{c}{ Valor } & Gl & $\begin{array}{c}\text { Sig. Asist. } \\
\text { (2 caras) }\end{array}$ \\
\hline Chi-cuadrado de pearson & $11,968^{*}$ & 4 & 0,018 \\
Razón de verosimilitud & 12,932 & 4 & 0,012 \\
Asociación lineal por lineal & 1,914 & 1 & 0,166 \\
N de casos válidos & 30 & & \\
\hline
\end{tabular}

${ }^{*} 8$ casillas $(88,9 \%)$ han esperado un recuento menor que 5 . El recuento mínimo esperado es 1,50 .
Como el $p$-valor hallada es de 0,018 , y el Valor $p=0,018<0,05$, se afirma que los métodos que aplica el docente se relaciona significativamente con el aprendizaje de los estudiantes de Educación Inicial de la Facultad de Educación de la Universidad Nacional José Faustino Sánchez Carrión.

\section{Prueba de hipótesis específica 2}

Ho: Los materiales didácticos que emplea el docente no se relaciona significativamente con el aprendizaje de las estudiantes de educación inicial de la facultad de educación de la universidad nacional José Faustino Sánchez Carrión.

Hi: Los materiales didácticos que emplea el docente se relaciona significativamente con el aprendizaje de las estudiantes de educación inicial de la facultad de educación de la universidad nacional José Faustino Sánchez Carrión.

\section{Tabla 29}

\section{Prueba Chi-Cuadrado}

\begin{tabular}{llll}
\hline \multicolumn{1}{c}{ Valor } & Gl & $\begin{array}{c}\text { Sig. Asist. } \\
\text { (2 caras) }\end{array}$ \\
\hline Chi-cuadrado de pearson & $12,399^{*}$ & 4 & 0,015 \\
Razón de verosimilitud & 13,585 & 4 & 0,009 \\
Asociación lineal por lineal & 9,794 & 1 & 0,002 \\
N de casos válidos & 30 & & \\
\hline
\end{tabular}

*7 casillas $(77,8 \%)$ han esperado un recuento menor que 5 . El recuento mínimo esperado es 0,83 .

Como el $p$-valor hallada es de 0,015 , y el Valor $p=0,015<0,05$, se afirma que Los materiales didácticos que aplica el docente se relaciona significativamente con el aprendizaje de los estudiantes de Educación Inicial de la Facultad de Educación de la Universidad Nacional José Faustino Sánchez Carrión.

\section{Prueba de hipótesis específica 3}

Ho: Las capacidades pedagógicas del docente no se relaciona significativamente con en el aprendizaje de los estudiantes de Educación Inicial de la Facultad de Educación de la Universidad Nacional José Faustino Sánchez Carrión.

Hi: Las capacidades pedagógicas del docente se relaciona significativamente con en el aprendizaje de los estudiantes de Educación Inicial de la Facultad de Educación de la Universidad Nacional José Faustino Sánchez Carrión.

Tabla 30

Prueba Chi-Cuadrado

\begin{tabular}{llll}
\hline \multicolumn{2}{c}{ Valor } & Gl & $\begin{array}{c}\text { Sig. Asist. } \\
\text { (2 caras) }\end{array}$ \\
\hline Chi-cuadrado de pearson & $17,255^{*}$ & 4 & 0,002 \\
Razón de verosimilitud & 17,630 & 4 & 0,001 \\
Asociación lineal por lineal & 10,312 & 1 & 0,001 \\
N de casos válidos & 30 & & \\
\hline
\end{tabular}

7 casillas $(77,8 \%)$ han esperado un recuento menor que 5 . El recuento mínimo esperado es 0,93 .

Como el $p$-valor hallada es de 0,002, y el Valor $p=0,002<0,05$, se afirma que la capacidad pedagógica del docente se relaciona significativamente con el aprendizaje de los estudiantes de Educación Inicial de la Facultad de Educación de la Universidad Nacional José Faustino Sánchez Carrión.

\section{DISCUSIÓN}

De acuerdo a los resultados de la investigación encontramos que el desempeño docente según los instrumentos aplicados, y luego de realizar la sistematización de los resultados por medio del SPSS y de los análisis Estadísticos de Chi-Cuadrado 
de Pearson, podemos establecer similitudes en lo que nos muestra la teoría científica y los antecedentes de investigaciones similares con la realidad práctica. Significa que los docentes de la Facultad de Educación en estudio tienen una elevada tendencia a presentar niveles buenos de desempeño.

Los resultados del presente estudio corroboran lo encontrado por:

Espinosa (2014), quien sostuvo que "El desempeño pedagógico de los docentes es bueno pues toma en cuenta los intereses, motivaciones y conocimientos previos de los alumnos como punto de partida en su clase, la cual siempre planifica previamente, procurando cumplir con las actividades allí programadas. Durante el desarrollo de las clases procuran aclarar dudas y reforzar el aprendizaje a través de actividades individuales y grupales, dentro y fuera del aula, aprovechando los recursos del entorno para el afianzamiento de los aprendizajes".

Aguirre (2009) sostiene que "con el apoyo de las técnicas estadísticas y para la muestra considerada se pudo concluir que existe relación en grado moderado, entre la percepción del desempeño del maestro guía y la motivación del alumno".

Monrroy (2012) Sostiene que "existe una correlación positiva entre rendimiento académico en matemática con las prácticas pedagógicas, responsabilidad en funciones laborales, relaciones interpersonales y con desempeño docente".

Bellido (2011) manifiesta que, existe relación entre rendimiento académico y desempeño docente en la Escuela Profesional de Ingeniería de Alimentos de la Facultad Ingeniería Pesquera y de Alimentos de la Universidad Nacional del Callao, en el año 2008, precisándose que esta asociación no es significativo se da porque los niveles alcanzados en las dos características que se miden se ubican en el nivel medio.

Se evidencia que el $p$-valor hallada es de 0,001, y el Valor $p=$ $0.001<0.05$, se afirma que el desempeño docente se relaciona significativamente con el aprendizaje de los estudiantes de Educación Inicial de la Facultad de Educación de la Universidad Nacional José Faustino Sánchez Carrión

También, como el p-valor hallada es de 0,01, y el Valor $p=0,01$ $<0.05$, se afirma que los métodos que aplica el docente se relaciona significativamente con el aprendizaje de los estudiantes de Educación Inicial de la Facultad de Educación de la Universidad Nacional José Faustino Sánchez Carrión

De la misma forma, se evidencia como el $p$-valor hallado es de 0,015 , y el Valor $p=0,015<0,05$, se afirma que los materiales didácticos que aplica el docente se relaciona significativamente con el aprendizaje de los estudiantes de Educación Inicial de la Facultad de Educación de la Universidad Nacional José Faustino Sánchez Carrión

Asimismo, como el p-valor hallado es de 0,002, y el Valor $p=$ $0,002<0,05$, se afirma que la capacidad pedagógica del docente se relaciona significativamente con el aprendizaje de los estudiantes de Educación Inicial de la Facultad de Educación de la Universidad Nacional José Faustino Sánchez Carrión.

\section{CONCLUSIONES}

El desempeño docente se relaciona significativamente con el aprendizaje de los estudiantes de Educación Inicial de la Universidad en estudio, propiciando así un genuino y verdadero desarrollo académico y profesional de los estudiantes en las aulas universitarias.

El tema de nuestra investigación es un gran desafío para aquellos docentes que son conscientes de su labor pedagógica en las aulas universitarias, puesto que, dependerá de las decisiones que considere en el proceso de enseñanza aprendizaje, la buena formación de sus estudiantes.

\section{BIBLIOGRAFÍA}

Aguirre, S.F.A. (2009), de la Universidad de Montemorelos, en su tesis titulada Desempeño docente y su relación con la motivación del alumno en la escuela de capacitación adventista salvadoreño. Tesis de posgrado Facultad de Ciencias Administrativas. Universidad de Monte Morelos , México.

Bellido, F.R.S. (2011), en su tesis titulada, Relación entre desempeño docente y rendimiento académico en la escuela profesional de ingeniería de alimentos de la Facultad de Ingeniería Pesquera y de Alimentos de la Universidad Nacional del Callao.

Espinosa, G.S.F (2014), Desempeño docente en el proceso enseñanza aprendizaje en el nivel de Educación Básico Superior del Centro Educativo Colegio de Bachillerato Ciudad de Portovelo, provincia del Oro, en el año lectivo 2013-2014. Tesis de titulación en Ciencias de la Educación. Universidad Técnica Particular de Loja , Ecuador.

Monroy, A.M. (2012) Desempeño docente y rendimiento Académico en matemática de los alumnos de la Institución Educativa de ventanilla, Callao. Tesis para optar el grado académico de maestría en Educación. Mención en evaluación y acreditación de la calidad de la educación. Universidad san Ignacio de Loyola.

palomino, F. (2012). El desempeño docente y la influencia que tiene en el aprendizaje de los estudiantes universitarios de la Unidad académica de estudios generales de la Universidad San Martín de Porres. Extraído desde: http://Cybertesis.unmsm.edu.pe. 